Cuadernos de Filología Clásica. Estudios Latinos

ISSN: 1131-9062

http://dx.doi.org/10.5209/CFCL.60930

\title{
Effingitur corporis forma: consideraciones sobre la prosopografía en las comedias de Plauto
}

\author{
Eduardo A. Gallego Cebollada ${ }^{1}$
}

Recibido: 6 de noviembre de 2017 / Aceptado: 5 de junio de 2018

Resumen. A pesar de que el número de estudios que centran su atención en la caracterización de los personajes del teatro griego y latino es ingente, la importancia que se concede a la descripción física o prosopográfica de los propios personajes todavía resulta parca en la actualidad. Frente a un número prácticamente inexistente de prosopografías en el drama griego, sorprende comprobar cómo en el teatro romano, particularmente en Plauto, no ocurre lo mismo. Aunque se sigue careciendo de investigaciones que estudien este aspecto, la vertiente prosopográfica en la descripción de los personajes en la comedia romana cobra un interés mucho mayor que en el caso del teatro griego. En este sentido, el examen de un conjunto de pasajes plautinos permitirá plantear un origen para este tipo de descripciones físicas, así como valorar la impronta retórica, la importancia y la finalidad de este procedimiento.

Palabras clave: Comedia; Plauto; Retórica; prosopografía; effictio.

\section{[en] Effingitur corporis forma: considerations on prosopography in Plautus' comedies}

\begin{abstract}
Although the number of studies that focus on the characterization of Greek and Latin theater characters is enormous, the importance given to the physical or prosopographical description is still limited today. Faced with a practically nonexistent number of prosopographies in the Greek drama, it is surprising to see how in the Roman theater, particularly in Plautus, this situation has changed. Portraying the physical appearance of the characters becomes important. For this reason, the examination of a set of prosopographies will allow us to establish an origin for this type of physical description as well as to review the rhetorical trace, importance and purpose of this procedure.
\end{abstract}

Keywords: Comedy; Plautus; Rhetoric; prosopography; effictio.

Sumario: 1. La prosopografía retórica y su relación con la comedia. 2. La prosopografía en las comedias plautinas. 3. Conclusiones. 4. Bibliografía.

Cómo citar: Gallego Cebollada, E.A., «Effingitur corporis forma: consideraciones sobre la prosopografía en las comedias de Plauto», Cuad. Filol. Clás. Estud. Lat. 38.1 (2018), 11-22.

El examen del aspecto físico de los personajes en el drama romano apenas ha suscitado atención en comparación con otras cuestiones. Dos razones fundamentales pue-

Universidad de Zaragoza

egcebollada@unizar.es 
den barajarse como hipótesis para este desequilibrio en los estudios. Por un lado, el controvertido interrogante que existe a propósito del empleo de un número limitado de máscaras por parte de los actores, lo que anularía cualquier conato de individualización a través de la descripción física. Por otra parte, la utilización en las piezas cómicas de personajes estereotipados, todos los cuales presentarían los mismos rasgos, haciendo innecesario aproximarse al estudio de su apariencia con detalle.

Naturalmente, la descripción de los personajes teatrales en las comedias latinas está indisolublemente ligado a conceptos como la tipificación, que tiende a la generalización de los rasgos identificativos, pero también a nociones como la caricaturización, que se define precisamente por la idea opuesta: la singularización y acentuación de unas particularidades físicas. Precisamente la caricaturización desempeñaba un papel fundamental en las obras plautinas, como pone de manifiesto Cèbe (1966). Para el investigador francés (Cèbe 1966, 47), Plauto potenciaría en gran medida la deformación de sus personajes a través de sus comportamientos y a través de sus acciones mímicas ${ }^{2}$. Frente a la pretensión de Terencio por dignificar y dulcificar los personajes de sus comedias, ${ }^{3}$ Plauto no renunció a pintar a algunos de sus protagonistas como auténticos fantoches a través de la caricatura. Esta caricatura encontraría su reflejo en las proporciones de las máscaras teatrales. Así, Wiles, que se muestra favorable al empleo de las máscaras desde época de Plauto (1991, 127-149), sostiene que el empleo de la máscara teatral potenciaría todavía más el componente farsesco del teatro plautino al concebir los rasgos físicos de los personajes como una inversión de las características imagines maiorum ${ }^{4}$. En oposición al realismo de las imagines, concebidas como una representación verosímil de los antepasados, las máscaras tendrían que acentuar los rasgos físicos y la desproporción de los personajes.

En este sentido, la propia descripción física de los personajes, esto es, su prosopografía, podría vincularse con la caricatura cuando se observa la forma en la que Plauto dibuja a sus protagonistas. Por consiguiente, en este estudio se aborda el examen de un conjunto de pasajes plautinos donde la prosopografía adquiere especial relevancia. El examen de los textos de las comedias nos conducirá a plantear un origen para este tipo de descripciones físicas tan recurrentes en el drama plautino, así como a valorar la impronta retórica, la importancia y la finalidad que adquieren en el conjunto de la producción del comediógrafo.

Cèbe $(1966,9)$ establece un modelo tripartito dentro de las caricaturas. Por un lado, aquellas ocupadas en desacreditar y destruir al caricaturizado, lo que fácilmente puede identificarse con el propósito de la invectiva. En segundo lugar, las caricaturas que, aunque también participan de la sátira, lo hacen mediante una ironía maliciosa y no a través de un sarcasmo hiriente. El último tipo reseñado no representa propiamente una caricatura, sino más bien un modelo de escritura humorística, basada en la deformación consciente del referente y privado de cualquier tipo de censura. Por sus condiciones histórico-culturales y por la ausencia de identificaciones personales dentro de las comedias, parece que los textos de Terencio y, sobre todo, Plauto se enmarcan en este apartado. Pociña Pérez $(1975,242)$ lo resumía perfectamente cuando afirmaba que una de las pretensiones de Terencio fue «dar a cada uno de sus personajes un cierto relieve personal que lo convirtiera en una persona determinada y no en un mero muñeco de guiñol».

4 El estudio de Wiles parece alimentar asimismo las hipótesis desarrolladas posteriormente por otros investigadores como Marshall (2006), para quien la máscara de las funciones teatrales de Plauto y Terencio sincretizaba los rasgos del teatro griego y la farsa atelana $(2006,126-158)$. 


\section{La prosopografía retórica y su relación con la comedia}

Como es bien sabido, los principios teóricos codificados en la retórica para la descripción física de un personaje son más tardíos que las obras de Plauto. El propio término «prosopografía» no se localiza en ningún manual de retórica antiguo, siendo

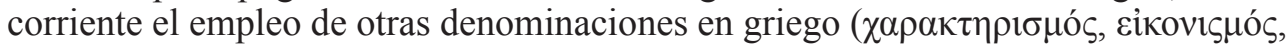
vं pictio $)^{5}$. Con todo, este argumento no puede esgrimirse para restar importancia al papel que la retórica ostentaba dentro de las descripciones físicas de la comedia. Antes bien, la retórica, sus codificaciones y el carácter prescriptivo que más adelante impondrá sobre los géneros literarios se convierten en buenos aliados a la hora de analizar el papel de la prosopografía en las comedias. Es más, ya Caplan (1954, 386 n. c), en su edición de la Retórica a Herenio, señalaba cómo el procedimiento de la effictio era «favoured in comedy». En efecto la prosopografía ocupa un lugar destacado dentro de la comedia latina - como también lo hará dentro de las piezas trágicas - ${ }^{6}$, algo que no ocurría dentro de la comedia griega, donde los versos en los que se utiliza son verdaderamente escasos ${ }^{7}$. Este hecho hace sospechar que en el intervalo que se extiende entre ambas manifestaciones pudiera haberse producido un cambio de paradigmas a la hora de elaborar las descripciones de los personajes cuyo resultado fuera otorgar mayor relevancia a la descripción del físico de los personajes, mayor importancia a su prosopografía.

El primer tratamiento retórico de esta figura en Roma (y quizá el más clarificador a la luz de los ejemplos posteriores) aparece en el libro cuarto del manual dedicado a Herenio. Respecto a la descripción del físico, el auctor se expresa de la siguiente forma (Rh. Her. 4.63):

Effictio est cum exprimitur atque effingitur uerbis corporis cuiuspiam forma, quoad satis sit ad intellegendum, hoc modo: «Hunc, iudices, dico, rubrum, breuem, incuruom, canum, subcrispum, caesium, cui sane magna est in mento cicatrix, si quo modo potest uobis in memoriam redire.» Habet haec exornatio cum utilitatem, si quem uelis demonstrare, tum uenustatem, si breuiter et dilucide facta est.

El modelado consiste en que la imagen del cuerpo de alguien se represente y reproduzca mediante palabras, de un modo que baste para reconocerlo, por ejemplo: «Me refiero, jueces, a este de color colorado, pequeño, corcovado, de pelo cano,

\footnotetext{
Vid. Artaza (1992, 163-166) para el resumen de los testimonios de la Antigüedad. El propio término prosopografía es también tardío en español. De acuerdo con el Corpus Diacrónico del Español, su primera aparición se da en la obra Guzmán el bravo (1623) de Lope de Vega. Resulta llamativo que dicha aparición tenga lugar en un contexto relacionado con la Antigüedad y con la retórica: «Y así pintó Luciano, retórico, aquella prosopografía de Hércules con el arco en la mano siniestra, la clava en la derecha, y en la boca aquellas cuerdas con que llevaba aprisionados innumerables hombres, para dar a entender que no con las fuerzas ni las armas los había vencido, sino con la elocuencia...».

6 En el caso de la tragedia senecana, la influencia es mucho más notoria como apuntaba certeramente Zapata Ferrer (1988, 380). Así, pueden considerarse Thyes. 330-331; H.F. 329-330; Ag. 128, 237-238, 710-719; Phae. 362-366, 646-656, 795-808; Tro. 448-450; Med. 387-389, 853-861; H.O. 250-253. Vid. Misener (1924) y Evans (1950) al respecto. Las consideraciones sobre el retrato, así como los mismos retratos, también abundan en la producción en prosa del filósofo. Por ejemplo, Ep. 52.12; 76.32; 83.20-21; 92.13; 95.65-66; 106.5; 114.3; Constant. 18.1; De ira 1.1.3-4; 2.35.3; 3.4.1-2.

7 Vid. Ar. Nu. 1009-1019; Thesm. 189-192 y Plut. 265-267, 559-561.
} 
algo encrespado, de ojos garzos, el que tiene una cicatriz realmente grande en la barbilla, si de esta forma os es posible recordarlo.» Tiene esta figura no solo utilidad, si quisieras identificar a alguien, sino especial encanto si se hace con brevedad y claridad. ${ }^{8}$

Como resulta natural, en el ejemplo que acompaña a la definición de la effictio ${ }^{9}$ abundan los adjetivos, que aparecen enumerados concatenadamente de forma asindética. Es interesante advertir cómo el autor elabora una auténtica descripción cinematográfica del personaje, comenzando por plantear un enfoque general para más adelante concretar su retrato prestando especial atención al rostro, que se describe de forma descendente (pelo, ojos, barbilla) ${ }^{10}$. Según se podrá comprobar, el procedimiento descriptivo que se observa en la Rethorica ad Herennium se asemeja bastante a las prosopografías que podemos encontrar en las comedias de Plauto, pero se diferencia del carácter con el que otros rétores posteriores vincularán esta práctica ${ }^{11}$.

A la hora de investigar el origen de este tipo de descripciones y su huella en los textos plautinos, debe considerarse la información que aporta Séneca sobre el procedimiento prosopográfico. En Séneca, este procedimiento aparece testimoniado como iconismos o, simplemente, como descriptio (Ep. 95.65-66). Sin embargo, este recurso tampoco tiene una identidad física unívoca. Los signa y las notas a los que se refiere el filósofo en su epístola están exclusivamente limitados al plano de las virtudes y los vicios de una persona. No obstante, en el mismo pasaje Séneca alude a los publicani, el gremio que se servía de esta práctica descriptiva. En efecto, la mención por parte de Séneca de los recaudadores de impuestos es interesante cuando se pretende rastrear el origen de la práctica prosopográfica o iconística. Así, el eícovisuós griego (o la effictio latina) fue definida por Misener $(1924,97)$ como «una breve descripción asindética de la apariencia personal diseñada como medio de identificación legal o como adorno de estilo». Tal y como demostraba en las primeras páginas de

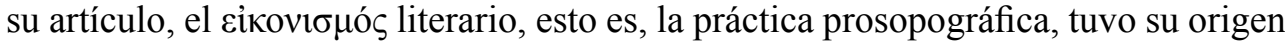
en la vida real (Misener 1924, 103), concretamente, en el método identificativo empleado en los papiros helenísticos procedentes del Egipto Ptolemaico.

Salvo que se indicara lo contrario, todas las traducciones ofrecidas son originales del autor del artículo.

A menudo el término effictio se traduce como 'retrato', pero el retrato, en tanto que figura retórica, supone la conjunción de la descripción física y moral de una persona. Una posibilidad para salvar este escollo terminológico sería traducir el latín como 'modelado', ya que en este caso, como en muchos otros, resulta evidente el vínculo que opera entre las artes plásticas y la práctica literaria, especialmente si se tiene en cuenta la etimología de la palabra (<*dheigh-) y de los términos con los que el autor se refiere a ella (exprimitur, effingitur, forma). A este respecto, Gladhill $(2012,328)$ matiza que el empleo de estos términos característicos de las artes plásticas no era un rasgo corriente en la Antigüedad, encontrándose, por lo general, en textos especializados de época tardía.

10 Con no pocas dificultades, quizá pudiera verse aquí cierta prefiguración del orden descendente, aquél que pasará a operar sobre los retratos en la literatura posterior. Si es cierto que la fijación de este proceso descriptivo tiene lugar durante la Antigüedad Tardía, no es menos cierto que este mecanismo no era desconocido para los autores precedentes, pues ya Quintiliano (Inst. 3.9.9) advertía sobre la imposibilidad de empezar a pintar o esculpir por los pies, vislumbrando lo que luego se un patrón literario más rígido.

11 Así, Rutilio Lupo (2.7) atribuye a la prosopografía un carácter mestizo, en el que se dan cita tanto la descripción física de un individuo como su descripción moral. Estas particularidades, como señala el rétor de época augústea, permiten a un autor dibujar aut uitia aut uirtutes de un personaje del mismo modo que lo haría un pintor. Más cercana a la effictio de Rh. Her. está la definición de otro autor de la misma época que Lupo, Trifón,

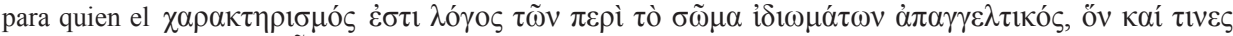

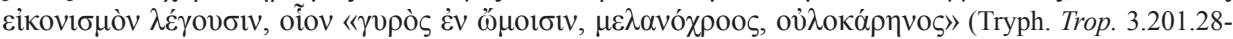
31 Spengel). Obsérvese que en este último se recurre a un verso homérico (Od. 246) en el que para describir a Euríbates los adjetivos también se organizan de forma asindética. 
En el contexto del Egipto helenístico, la función de la prosopografía era meramente identificativa. Este procedimiento era recurrente cuando los escribas necesitaban dejar constancia de la participación de un individuo que no sabía leer ni escribir $y$, por lo tanto, era incapaz de rubricar el documento de una transacción en la que se viera envuelto. A este respecto, el ejemplo más antiguo que he localizado en los dos volúmenes editados por Hunt y Edgar (1932-1934) data del 245 a. C. Se trata de una declaración testimonial en la que un tal Eufronio testifica a favor de Antípatro. Eufronio se encontraba en una barbería con Nicón, de quien Antípatro solicita que le devuelva a su hijo Teodosio ${ }^{12}$; su propósito, por tanto, es claramente identificativo y no puede aventurarse que la descripción del retratado contenga otra finalidad que la puramente práctica y objetiva: reconocer a una persona ausente.

Este tipo de descripciones de carácter identificativo y que se mantendrán durante el dominio romano de Egipto resultaban mucho más frecuentes en los siglos III y II a. C. que en las centurias posteriores, en las que la práctica identificativa de un individuo quedó prácticamente eclipsada por la fórmula oủ con una cicatriz o sin marca identificativa, junto con la expresión de la edad y la filiación ${ }^{13}$. Resulta sorprendente el grado de semejanza en la construcción de estas descripciones con las prosopografías plautinas que conocemos en las que se describe a los lenones y a los esclavos ${ }^{14}$. Los testimonios papiráceos más abundantes en los que se emplea este recurso como medio identificativo se localizan en el período helenístico, una época en la que proliferaron los manuales de retórica. Como consecuencia, resultaría sugerente establecer una hipotética secuenciación cronológica en virtud de la cual un proceder meramente administrativo - una práctica burocrática - fue, poco a poco, adquiriendo carta de naturaleza propia y aislándose de su contexto, para terminar convertido en una figura en el seno de los manuales de retórica y en un recurso ornamental de la mano de algunos autores como Plauto. El análisis y la comparación de algunos pasajes plautinos en los que resulta evidente el empleo de la prosopografía permitirá refrendar esta hipótesis.

\section{La prosopografía en las comedias plautinas}

A propósito de las características físicas de los personajes de la palliata, Hough elaboró en la primera mitad del siglo xx un valioso inventario con treinta y un pasajes plautinos y terencianos ${ }^{15}$. En todos estos pasajes, significativamente breves, se detallaba la apariencia exterior de diferentes personajes, siendo los casos del lenón

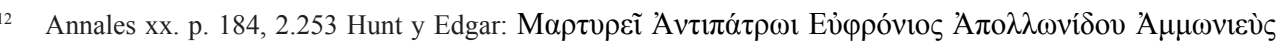

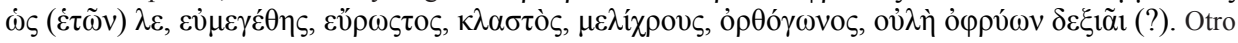
ejemplo interesante data del 129 a. C., en este caso, una mujer llamada Senutis y su tutor, Harsiesis, venden diez días libres de los que pueden disfrutar cada año (P.S.I. 1016, 11.16-37, 1.37 Hunt y Edgar).

13 Curiosamente, el ejemplo de Rh. Her. propuesto para la effictio también incluye la descripción de un sujeto con una cicatrix. Ejemplos en P. Fay. 91, 1.17 Hunt y Edgar; P. Tebt. 303, 2.248 Hunt y Edgar; P. Oxy. 95, 1.32 Hunt y Edgar; P. Lond. 334, 1.76 Hunt y Edgar; P. Tebt. 380, 1.54 Hunt y Edgar; P. Tebt. 392, 1.58 Hunt y Edgar; P. Ryl. 174, 1.74 Hunt y Edgar.

14 Sobre todo, estos últimos. Así, Misener (1924, 102-103) apunta la semejanza de algunas descripciones plautinas de esclavos con un papiro (datado en 145 a. C.) en el que se brinda información sobre un esclavo fugitivo (Par. P. 10).

15 Como advertía el mismo Hough, su recuento excluye veintidós casos en los que se presentan cualidades parti- 
y del esclavo los más abundantes. A la luz de los atributos descritos en estos versos, Hough concluía que las descripciones referidas podían clasificarse de acuerdo a dos variedades. Por un lado, se hallarían presentes en las comedias pasajes cuya finalidad era simplemente identificativa ${ }^{16}$. Sin embargo, la inmensa mayoría correspondería a una finalidad humorística, que se convertiría en el objetivo principal por el que se emplearían tales apuntes descriptivos (Hough 1943, 87). Ahora bien, muchos de los pasajes citados no llegan a constituir una effictio o prosopografía del personaje, ya que solo se brinda información sobre una determinada parte del rostro o del cuerpo de este, como el cabello (As. 934: Men. 838) o los ojos (Cur. 392), pero que no dibujan su físico de forma detallada ${ }^{17}$. Por este motivo, los ejemplos aquí seleccionados para el estudio de la prosopografía plautina se limitarán a siete pasajes en los que el retrato físico del personaje es completo o, por lo menos, muy detallado ${ }^{18}$.

2.1. Uno de los personajes más propensos a la effictio en las obras de Plauto es el lenón. A este respecto, Rudens, contiene un par de descripciones (124-127 y 316320) que pueden resultar ilustrativas. En ambos casos se hace referencia al lenón Lábrax ${ }^{19}$.

PL. Dic quod te rogo,

ecquem tu hic hominem crispum, incanum uideris, malum, periurum, palpatorem... DA. Plurumos, nam ego propter eius modi uiros uiuo miser.

PlesediPo. Respóndeme a lo que te pregunto, ¿tú has visto por aquí a cierto tipo de pelo rizado, tirando a cano, un bellaco, un perjuro, un marrullero...?

DÉmONES. A muchísimos, pues yo vivo como un desgraciado por hombres de esta calaña.

PI. Nullum istac facie ut praedicas uenisse huc scimus. TR. Ecquem

recaluom ac Silanum senem, statutum, uentriosum,

tortis superciliis, contracta fronte, fraudulentum,

deorum odium atque hominum, malum, mali viti probrique plenum,

qui duceret mulierculas duas secum satis uenustas?

Pescadores. No sabemos que haya venido por aquí ninguno con una pinta como el que has mencionado antes.

TRACALIÓn. ¿Y a alguno calvo por la parte de delante como el viejo Sileno, grande, barrigudo, de cejas fruncidas, de frente arrugada, un timador, un enemigo para los dioses y las personas, un bellaco, lleno de funestos defectos y de infamia, que llevaba consigo dos mujercitas bastante monas?

culares conectadas a circunstancias puntuales, pero ajenas a las características físicas. Asimismo, quedan fuera de este inventario seis pasajes pertenecientes a la literatura fragmentaria, dada la imposibilidad para determinar su contexto (1943, 86 n. 1).

16 A excepción del caso de Mil. 631.

17 Los versos de Plauto que se citan en el artículo son As. 400, 934; Capt. 647; Cas. 466, 518; Cur. 231, 392; Epid. 620; Men. 838, 854, 864; Mer. 639; Mos. 275; Mil. 631, 768, 923, 1306; Poen. 1416; Ps. 659, 968, 1040, 1218 ; Rud. 125, 313, 317, 422; Truc. 287, 610.

18 Los pasajes en cuestión son Rud. 124-127, 316-320; Mer. 638-641; Ps. 1217-1220; As. 399-402; Capt. 646-648; Poen. 1111-1114.

19 Cf. Rud. 650-653, aunque aquí no se menciona ningún rasgo físico, y Cur. 230-233, donde el lenón Capadocio es reconocible por presentarse cum collatiuo uentre atque oculis herbeis (231). 
Si bien es inevitable encontrar abundantes referencias al carácter de los lenones (malum, periurum, palpatorem, fraudulentum), ambas descripciones también cuentan con una buena dosis de adjetivos que retratan físicamente al individuo especificando sus rasgos más reconocibles. Los dos retratos, en virtud de su semejanza, parecen estar construidos de una forma sinóptica. Ambas effictiones, por ejemplo, se encuentran respondiendo a una modalidad interrogativa. Este dato puede resultar una obviedad, pero conduce a pensar que Plauto, en línea con su generalizado descuido o desinterés por la pintura de individuos diferenciados, concibe el retrato físico como una disertación que precisa estar demandada por el receptor. Sin ir más lejos, obsérvese cómo en un caso Plauto se refiere a Lábrax como crispum (125) y, un poco más adelante, lo hace como recaluom (317). Si bien se podría pensar que no se trata de una contradicción, puesto que una persona con el pelo rizado puede estar perfectamente falta del mismo por la parte delantera de la cabeza, el ejemplo parece lo suficientemente sintomático de la displicencia en la lógica descriptiva plautina ${ }^{20}$. Por otro lado, también cabe considerar que el esquema pregunta-respuesta se trata del método más cómodo y eficaz para amplificar el contenido de cualquier escrito, ya que toda interpelación a un personaje debe ir acompañada generalmente de un(os) verso(s) o fragmento de verso para contestar. Esta misma condición hace posible tanto la supresión del retrato sin que la trama de la comedia se vea comprometida en modo alguno, como la inserción de estos paréntesis descriptivos donde mejor le convenga al comediógrafo.

En segundo lugar, merece atención la profunda impronta de la fisiognomía en el segundo retrato, detectable sobre todo en dos aspectos. Por un lado, la comparación con el anciano Sileno (317), que da pie a un juego de palabras, y por otro lado, los sintagmas tortis superciliis y contracta fronte (318). El juego de palabras al que alude Plauto se sustenta en la paronimia que se establece entre Silanum y Silenum, ya que en ambos casos se hace referencia a un individuo de nariz chata (silus) ${ }^{21}$. Por otro lado, esta suerte de animalización propicia la entrada en juego de la fisiognomía, en concreto, la auspiciada en los métodos zoológicos, vinculando de esta manera a Lábrax con Sileno, al que se identifica siempre con un comportamiento lujurioso, como el de un macho cabrío ${ }^{22}$. Por otra parte, los dos sintagmas antes mencionados (318) apuntalan todavía más la importancia de la conciencia fisiognómica. En efecto, de los dos enfoques restantes - etnológico y etológico - sobre los que se basaba esta ciencia según el manual de Pseudo-Aristóteles ([Phgn.] 805a), aquí se prioriza el etológico, aquel que vincula los rasgos físicos y las características asociadas a cada uno de ellos con una inclinación temperamental. Es así que tener el ceño fruncido y la frente arrugada era un acerbi animi indicium ${ }^{23}$. Otro rasgo más que, sumado a la desproporción corporal con la que presenta Plauto al lenón, acentuarían todavía más la vileza de este personaje.

2.2. No obstante y pese a lo dicho a propósito de este tipo de descripciones, operar

\footnotetext{
Ya el propio Horacio (Ep. 2.1.70 ss.) señalaba estas incoherencias.

21 Ussing (1972: 385) cita apropiadamente a Plinio en este punto: Non alii animalium (quam homini) nares eminent; auibus, serpentibus, piscibus foramina tantum ad olfactus siue naribus, et hinc cognomina Simorum, Silonum (Plin. NH. 11.158).

22 Téngase en cuenta que el oficio del lenón se caracteriza por el comercio carnal. Asimismo, recuérdese la asimilación de la barba de su compañero de gremio, Balión, $(P s .967)$ con la de una cabra.

23 Vid. contracta fronte en Ussing $(1972,385, s$. v.). La fisiognomía se encontraba a la orden del día en la sociedad romana de tiempos de Plauto. El artículo de Montero (1993, 77-82), en el que se analiza la presencia de una 'lectora de cejas' en Miles gloriosus, que se servía de un método propiamente fisiognómico, aporta interesantes
} 
con las effictiones en la comedia resulta complicado. Obsérvense los siguientes versos de Mercator (638-641):

CHAR. Qua forma esse aiebant <igitur>? EVT. Ego dicam tibi: canum, uarum, uentriosum, bucculentum, breuiculum, subnigris oculis, oblongis malis, pansam aliquantulum.

CHAR. Non hominem mihi, sed thensaurum nescio quem memoras mali. CARINO. ¿Qué aspecto decían que tenía entonces?

Eutico. Yo te lo voy a decir: canoso, patizambo, barrigudo, de boca grande, pequeñajo, los ojos tirando a negros, de carrillos pronunciados, un poquito anchos los pinreles.

CARino. Me da que no te estás acordando de una persona, sino de no sé qué almacén de calamidades.

Como se puede comprobar, la gran mandíbula, el vientre abultado y, en general, la acumulación de defectos (thensaurum mali), parecen inducir a pensar que el personaje por el que pregunta Carino se trata de un lenón, tal y como sucedía en los pasajes anteriores. No obstante, Eutico está describiendo al viejo Lisímaco, un personaje secundario. Sin ánimo de comentar los versos más pormenorizadamente, diremos que, si se desconociera el contexto de estos, tan solo podría detectarse un indicio específico para vincular esta descripción a un senex, el color canum del pelo ${ }^{24}$. Más interesante, en cualquier caso, es advertir la semejanza en el procedimiento descriptivo, que, como en los ejemplos previos, presenta el esquema pregunta-respuesta, y el hecho de que los atributos en los que se focaliza la atención sean siempre los mismos, aquellos que evidentemente pueden ser modificados para disfrazar al actor y caricaturizar al personaje: el color de la peluca (canum); el calzado (pansam aliquantulum y, probablemente, uarum); la barriga (uentriosum), que podría lograrse rellenando el palio de diversas maneras; y la serie de atributos correspondientes a la máscara (bucculentum, subnigris oculis, oblongis malis).

2.3. Como ocurría con los lenones, la effictio de los esclavos se encontraba igualmente tipificada en el proceder plautino. Un ejemplo es el siguiente diálogo entre Hárpax y Balión en Pseudolus (1217-1220):

BA. Eho tu, qua facie fuit, dudum quoi dedisti sumbolum?

HA. Rufus quidam, uentriosus, crassis suris, subniger, magno capite, acutis oculis, ore rubicundo, admodum magnis pedibus.

BALIÓN. ¡Eh, tú!, ¿qué pinta tenía ese al que le diste la contraseña hace nada?

HÁRPAX. Un tipo pelirrojo, barrigudo, de piernas gordas, tirando a moreno, cabezón, de mirada perspicaz, con el rostro colorado, con los pies muy grandes.

Uno de los elementos que aparecen de forma reiterada en los lugares anotados por Hough y que también se encuentra presente en el texto reproducido es el color del

notas al respecto.

24 Efectivamente, este es era el color de las pelucas de los ancianos, mientras que el lenón, como transmite Pólux,

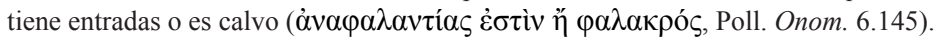


cabello. El color del pelo de un esclavo acostumbraba a ser pelirrojo. Como es bien sabido, esto se debía a la peluca que llevarían los actores y que se convertía desde el principio de la representación en un signo inequívoco de su condición y en un indicio del comportamiento que iban a desarrollar durante la obra. En este punto, una vez más, puede apreciarse la estrecha conexión que mantenía el atrezo y la descripción física con el universo conceptual de la comedia. Así, el mismo Pólux (Onom. 6.149150) recalcaría que, dentro de las máscaras de esclavos, todas ellas excepto una - a causa de su senectud - presentaban esta tonalidad en el cabello, lo que muchas veces se encontraba asociado a nombres como Jantias o Pirrias (Wiles 1991, 138, 152, 165-166). Lo mismo cabe decir de otros rasgos como la mirada, que en los esclavos normalmente denota sagacidad, malicia y picardía. Por tanto, el retrato físico de muchos personajes, tomado como codificación verbal de una información visual, respondía también a los mismos convencionalismos de la escena romana: una máscara caricaturesca y un comportamiento caricaturesco llevaban inexcusablemente aparejada una descripción física caricaturesca.

2.4. Asimismo, como se ha venido señalando, este tipo de retratos no tratan tanto de adaptarse a la realidad de un personaje como de actuar a guisa de soporte cómico. Como si de gags se tratara, tales descripciones a veces se prestan a algunas contradicciones o equívocos, que revelan cómo su verdadero sentido era provocar la risa antes que retratar de una forma fiel. Un buen ejemplo puede localizarse en Asinaria (399-402), cuando un mercader interroga a Líbano sobre el aspecto de Saúrea.

ME. Qua facie uoster Saurea est? Si is est, iam scire potero.

LI. Macilentis malis, rufulus aliquantum, uentriosus,

truculentis oculis, commoda statura, tristi fronte.

ME. Non potuit pictor rectius describere eius formam.

Mercader. ¿Qué pinta tiene vuestro amigo Saúrea? Si es él, lo podré saber a la de ya.

LíBANO. De mejillas demacradas, bastante pelirrojillo, barrigudo, de mirada amenazadora, de estatura mediana, de gesto implacable.

MERCADER. ¡No podría un pintor haber perfilado mejor su figura!

Saúrea es un esclavo dotal. Sin embargo, el personaje que en realidad está describiendo Líbano no es Saúrea, sino Leónidas, otro esclavo a su vez. Lo cierto es que poco importa. La descripción de un esclavo bien podía emplearse para caracterizar a otro personaje de la misma condición. Por esta razón, el mercader responde muy agudamente, alabando el número de detalles, al tiempo que ironiza sobre la calidad descriptiva de Líbano. Los rasgos principales que hacen posible la identificación casi siempre coinciden y casi nunca son positivos. El cabello pelirrojo y/o el rostro rojizo (rufus; rubicundo; rufulus), el vientre hinchado (uentriosus) y la mirada sagaz o, incluso, desafiadora, se convierten en señas inequívocas (acutis / truculentis oculis).

2.5. Pero, ¿puede afirmarse que se trate siempre de señas inequívocas? Préstese atención al siguiente diálogo de Captiui (646-648), en el que Hegión pregunta a Aristofonte por el semblante de uno de los prisioneros. 
HE. [...] Sed qua faciest tuos sodalis Philocrates? AR. Dicam tibi:

macilento ore, naso acuto, corpore albo, oculis nigris,

subrufus aliquantum, crispus, cincinnatus.

Hegión. [...] Pero, ¿qué pinta tiene tu compañero Filócrates?

Aristofonte. Te lo voy a decir: de cara chupada, nariz afilada, tez blanca, los ojos negros, tirando a algo pelirrojo, pelo rizado, ensortijado.

En esta obra, como en Anfitrión, Plauto explota el motivo del doble. Los dos cautivos, Filócrates y su esclavo Tíndaro, habían intercambiado sus papeles al comienzo de la representación (Capt. 37-39). En la descripción que se hace de Filócrates Tíndaro, en realidad - se le considera pelirrojo (subrufus aliquantum), pero, tal y como se ha anunciado previamente en el prólogo (Capt. 17-21), el propio Tíndaro es también un ciudadano libre, hijo del anciano Hegión. Quizá por este motivo se aplique al cabello del personaje el adjetivo cincinnatus, en referencia al peinado adornado de algunos jóvenes. Consecuentemente, ni Filócrates ni Tíndaro deberían estar caracterizados mediante una peluca pelirroja, pero parece que esto poco importa a Plauto, quien en este caso antepone el código visual del retratado en la ficción, esto es, el tradicional color pelirrojo del esclavo, al convencionalismo de la escena, según el cual los ciudadanos libres aparecían representados con el pelo de diversos colores en función de su edad (negro, blanco), pero nunca rojizo.

2.6. Quizá tales ejemplos descriptivos llegaron a constituir una categoría empática demandada en cierta manera por el espectador. Al menos, esta sería una de las ideas que podrían barajarse cuando se tiene en cuenta que la fugaz reseña de los atributos físicos de personajes como el esclavo o el lenón también fue importada a otros casos mucho menos importantes. Este es el caso del siguiente retrato de un personaje secundario, la nodriza de Poenulus (1111-1114).

HAN. Sed earum nutrix qua sit facie, mi expedi.

MIL. Statura hau magna, corpore aquilost. HAN. Ipsa east.

MIL. Specie uenusta, ore atque oculis pernigris.

HAN. Formam quidem hercle uerbis depinxti probe.

HANón. Pero su nodriza, explícame qué pinta tiene.

MiLción. No es de gran talla, de cuerpo oscuro.

HANÓN. Es ella en persona.

MiLción. De apariencia agradable, el rostro y los ojos muy negros.

HANÓN. No hay duda, por Hércules, de que has dibujado estupendamente su físico.

Tanto en este ejemplo (depinxti, v. 1114), como en el de Asinaria (pictor, v. 402), los personajes actúan como auténticos pictores, que tratan de esbozar rápidamente el perfil del individuo por el que se les pregunta. En una comedia motoria no hay tiempo para dilaciones, todo se realiza de una forma apresurada y, por este motivo, las descripciones solo contienen los rasgos físicos más relevantes: tamaño, color de ojos, color del rostro. El color negro del rostro de la nodriza se encuentra argumentalmente explicado, pues la propia nodriza y las muchachas de la obra habían sido raptadas en el barrio cartaginés de Magara (Poen. 86). No es necesario observar aquí, como hacía Della Corte $(1975,172)$, una contradicción con el catálogo de máscaras transmitido por Pólux, que no contiene ninguna de color negro. La compañía podría haber empol- 
vado perfectamente el rostro de la máscara con hollín o cualquier otro elemento para lograr la apariencia requerida sin necesidad de modificar de esta manera los elementos de atrezo. Por lo demás, la prosopografía de la nodriza es una rara avis en el marco de las comedias de Plauto ya que se trata del único ejemplo en el que este modo de proceder se aplica a un personaje femenino dentro de la obra del Sarsinate ${ }^{25}$.

\section{Conclusiones}

Tal y como se ha podido comprobar, las descripciones del físico de los personajes en Plauto son numerosas y recurrentes a lo largo de distintas comedias. Además de esto, todas las prosopografías que se han analizado presentan una serie de rasgos comunes que hacen posible aislarlas y concebirlas como teselas dentro una estructura más compleja en la que cada comedia se asemejaría a un mosaico. Así, en primer lugar debe notarse la importancia del contexto interrogativo dentro de estas prosopografías. Por norma general la effictio tiene como propósito inmediato responder a una cuestión que se ha desarrollado con anterioridad y en la que se pregunta por el aspecto de un personaje ausente en ese momento.

Un segundo elemento digno de atención lo constituye la preponderancia que el rostro adquiere en estas descripciones. En efecto, las prosopografías centran su atención en los atributos físicos del rostro y la cabeza del personaje. Aunque hay referencias al tamaño del vientre o la estatura del actor, lo corriente es que la descripción priorice aquellos rasgos que serían más fácilmente codificables mediante el empleo del atrezo y, de modo particular, mediante el uso de una máscara cuyas facciones podrían haberse visto deformadas de un modo caricaturesco. Junto a esto, debe observarse que todas estas prosopografías muestran un elevado grado de semejanza que se concreta, por ejemplo, en la repetición de buena parte de los adjetivos empleados y en la construcción asindética de estos. Este parecido, unido a la brevedad de todas ellas, deriva en que las mencionadas prosopografías apenas se encuentren integradas en las piezas o lo hagan de una forma tal que su eliminación no altere en modo alguno la arquitectura de la obra.

Todas estas consideraciones parecen herederas de los primeros testimonios prosopográficos que conocemos, aquellas descripciones conservadas en los papiros egipcios de época helenística. Según se ha evidenciado, la práctica legal de la effictio o

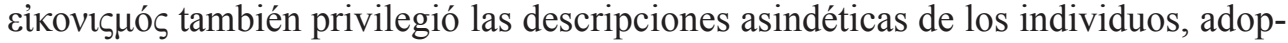
tando una configuración que - a la luz de los ejemplos propuestos - bien podrían haber heredado posteriormente manifestaciones como la comedia. De este modo, las prosopografías de los personajes cómicos, que para los espectadores podrían haber llegado a constituir una categoría empática reconocible y demandada, suministrarían un material más que provechoso para disciplinas como la retórica, que se encargaría de privarlas de su acostumbrada finalidad humorística para teorizar y codificar la descripción física de un personaje.

25 Junto a este caso, solamente conservamos la prosopografía del colectivo de las prostitutas en Cist. 405-408. La transmisión fragmentaria de la obra y las lagunas entre las que se enmarca el texto impiden pronunciarse con certeza respecto al mismo. A las notas sobre su comportamiento (limaces lividae, febricul $<$ osae, mi $>$ serae amicae...diobolares, schoeniculare) se suma unos epítetos y descripciones del físico realmente desagradables (ossae...miraculae, cum extertis talis, cum todillis crusculis). 


\section{Bibliografía}

Artaza, E. (1992), «Charakterismós», en G. Ueding (ed.), Historisches Wörterbuch der Rhetorik, Tubinga, Niemeyer, 163-166.

Caplan, H. (1954), Ad. C. Herennium. De ratione dicendi, Cambridge, Harvard University Press.

Cèbe, J.-P. (1966), La caricature et la parodie dans le monde romain antique. Des origenes a Juvénal, París, E. de Boccard.

Della Corte, F. (1975), «Maschere e personaggi in Plauto», Dioniso 44, 163-193.

Evans, E. C. (1950), «A Stoic aspect of Senecan drama: Portraiture», TAPhA 81, 169-184.

Gladhill, B. (2012), «The Emperor's No Clothes: Suetonius and the Dynamics of Corporeal Ecphrasis», Cl Ant 31(2), 315-348.

Hough, J. N. (1943), «Descriptions of Physical Characteristics in Comedy», CW 37(8), 8687.

Hunt, A. S. y Edgar, C. C. (1932-1934), Select Papyri, Cambridge, Loeb Classical Library [Vol. 1 Non-literary papyri. Private affairs (1932); vol. 2 Non-literary papyri. Public Documents (1934)].

Lindsay, W. M. (1984 [=1904 vol. 1, 1905 vol. 2]), T. Macci Plavti Comoediae, 2 vols., Oxford, Clarendon Press.

Marshall, C. W. (2006), The Stagecraft and Performance of Roman Comedy, Cambridge, Cambridge University Press.

Misener, G. (1924), «Iconistic portraits», CPh 19(2), 97-123.

Montero, S. (1993), «Plauto, Mil. 694 y los primeros metoposcopoi latinos», Dioniso 63, 77-82.

Pociña Pérez, A. (1975), «Recursos dramáticos primordiales en la comedia popular latina», CFC 8, 239-276.

Spengel, L. von (1853-1856), Rhetores Graeci, 3 vols., Teubner, Leipzig.

Ussing, J. L. (1972 [=1875-1892]), Commentarius in Plauti Comoedias, Hildesheim, Georg Olms.

Wiles, D. (1991), The Masks of Menander: Sign and Meaning in Greek and Roman performance, Cambridge, Cambridge University Press.

Zapata Ferrer, Mª A. (1988), «Descriptiones en las tragedias de Séneca», CFC 21, 373-380. 